\title{
You Say Goodbye, I Say Hello
}

\section{Barry Trott, guest columnist}

Correspondence to this column should be addressed to Laurel Tarulli, Dalhousie University, School of Information Management, Halifax, Nova Scotia; email: laureltarulli@yahoo.com.

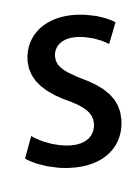

aying goodbye has never been a favorite part of my life. For the past eight years, beginning with RUSQ 44:3, I have been privileged to edit the readers' advisory column. What a wonderful time it has been. I have had the chance to talk with and work with some of the best writers and practitioners in the readers' advisory world. I will be forever grateful that they took the time out of their busy work schedules to put together articles for the journal, sharing their expertise and building a stronger readers' advisory community through these pieces. As I move on to take up the role of editor of RUSQ, I want to use this last column, or at least the first part of it, to both reflect and to look forward.

I would be remiss in leaving not to thank several people, without whom I would not have been able to make the column as good as it has been. First would be the editors of RUSQ. I have had the good fortune to work with three superb editors. In 2004, Danny Wallace and Connie Van Fleet were generous enough to offer me the position of RA column editor for RUSQ, and to get me started in the business of finding authors and crafting articles. I learned a great deal from them about working with word counts, manuscripts, writers, and deadlines, and I am grateful for their guidance. When Danny and Connie finished their terms, I was fortunate to have the opportunity to work for Diane Zabel. For the past six years, Diane has encouraged and enthusiastically supported the readers' advisory column. The articles that have appeared in the RA column are in part a tribute to Danny, Connie, and Diane's patience and attention to detail. Any column editor would be lucky to have worked with and for three such fine readers and editors. I would also like to thank all of the authors who have written for the column. To me, their pieces reflect some of the best thinking about the intersection of reading, readers, and librarians. It is not always a simple thing to write a column to someone else's schedule and to accept editorial suggestions. Each of the authors I have worked with has done both of these things with grace and style.

In developing the readers' advisory column, I was building on the work of Mary K. Chelton, who had previously edited the column. Under Mary K.'s guidance, the RA column offered the RUSQ community articles that presented practical advice about working with readers as well as examinations of the recent history and potential future of readers' advisory services in the United States. Her work was indeed a firm foundation on which to build. In the past eight years, the readers' advisory column has sought to blend theory and practice, looking not only at how to work with readers but also at why readers' advisory is essential in all sorts of 


\section{READERS' ADVISORY}

libraries. Articles have covered a wide range of topics: book discussion groups (in both public and academic libraries as well as online), form-based readers' advisory, RA in library school education, theories of genre separation (one of my favorite topics), fiction and the brain, and readers' advisory and the library catalog among others. In each of these cases, and in the other articles too numerous to mention, the authors looked for new ways to approach readers and reading and began a conversation that often carried over into the broader RA world. That really is the goal, I believe, for any column, that it serve not as an ending point but as a beginning for reflection, discussion, and then application of the ideas it promotes.

A real strength of RUSA is its varied and passionate membership. The opportunity to work with librarians outside your type of library is one that should not be under-valued. During my time in RUSA, and in particular as a column editor for RUSQ, I have learned a great deal from working closely with academic librarians and LIS faculty as well as with librarians in non-traditional roles. I hope that they have had the same experience in working with public librarians. The readers' advisory column has been a meeting ground where academic, school, and public librarians, readers' advisors in non-library settings, and LIS faculty have been able to come together to share ideas and practices, improving readers' advisory services in all our institutions.

The first decade of the twenty-first century has been an exciting time for readers' advisors. Building on the work of Joyce Saricks, Merle Jacob, Duncan Smith, Mary K. Chelton, and many others, readers' advisory librarians have taken the art of working with readers to new heights. This column has sought to publicize and promote new ways of thinking about RA work. Services to nonfiction readers have blossomed in the RA world. Online readers' advisory service has expanded in many libraries. Readers' services are now being explored in a more concrete fashion in the academic library. Whole collection readers' advisory is now an important piece of the RA discussion. Libraries are increasingly looking at how social reading tools can play a role in their practice. Digital formats have created challenges for librarians, including in readers' advisory services. All of these topics and many more have been discussed and explored in the readers' advisory column. One of the satisfactions of editing a column like this is finding those people who are shaping the profession and offering them a platform to share their work, reaching, perhaps, a wider audience than might otherwise be available to them.

Writing about what we do is an exercise that benefits not only the audience to whom we write but also benefits the writer. Putting thoughts and ideas on paper (or more frequently these days on computer), challenges us to think about what we do, and in so doing to develop a more coherent practice. My hope is that more librarians, particularly those in public libraries, will take the opportunity to write about not only what they are doing, but why they are doing it, and how their work fits into the long and storied history of readers' advisory services. It is too easy in the digital age to only think about the newest technology. We also need to try to place our work in the broad context of librarianship and our roles as librarians and readers' advisors. By doing so, we will both strengthen our current practice and ensure a robust future for readers' advisory.

So, I wish you all well, and I am very excited to turn over both this particular article, and the editorship of the RUSQ readers' advisory column to Laurie Tarulli. I am confident that under her guidance the column will continue to expand the boundaries of readers' advisory services, and to be a place where all those interested in working with readers, viewers, and listeners can come together to share ideas, debate practices, and carry RA service on into the next decade for the twenty-first century.

\section{INTRODUCTION, EXCITEMENT, AND AN INVITATION TO YOU}

It is with great excitement and perhaps a twinge of trepidation, that I begin this role as editor of the RA column in RUSQ. For almost a decade, Barry's devotion and interest in readers' services has provided all of us with thoughtful reflection, innovative ideas, and a reaffirmation of our own interest in readers' services. For many of us, this column has been a way to improve our in-house readers' services, providing us with insight from a variety of dedicated and passionate professionals. Knowing the popularity this column has enjoyed under his guidance and those who came before him, it is my wish to continue Barry's legacy, while adding my own "flavor" to the column. I know I have big shoes to fill and a lot of hard work ahead of me. But, from what Barry has told me, it's incredibly rewarding.

I was introduced to the world of readers' services in 2007. As part of a readers' service team, my main objective was to introduce the catalog into readers' services and find ways for the catalog to support existing readers' services practices within the library. What I soon found was that a disconnect existed between frontline readers' advisory staff and backroom librarians. And, further, this situation was not unique to one library, but to many larger library systems that supported a strong readers' advisory service. It appeared that while many smaller libraries were making use of all levels of staff with the understanding that even backroom staff have a leading role to play in enhancing readers' services, many larger libraries were struggling with a break-down in collaboration or lack of dialogue between frontline expertise and backroom expertise. However, backroom tools play a vital role in shaping the future of readers' advisory services

At the time I was introduced to readers' advisory work and given my position as cataloging librarian, it is not surprising that I developed an interest in using the library catalog as a prominent RA tool. I felt that the potential of the catalog, as well as the catalogers' themselves, were untapped resourcesnot just at my own library, but in libraries throughout North America. While we have traditionally relied on a variety of print and electronic readers' advisory tools, the library catalog 
has never really been explored beyond a last resort database for readers' advisory services-a static inventory that can provide access to pre-structured reading lists or suggested books that were found in other sources.

Since the start of my involvement in readers' advisory work, I'd walk away from meetings, training sessions, and conferences with my head buzzing with ideas, thinking of ways to enhance readers' services using the catalog. But more important, looking for opportunities to approach and speak with frontline readers' advisors to feed my growing hunger for readers' services knowledge and skills. As a backroom librarian, I felt cut-off from the rest of my RA colleagues and began to believe that not enough collaboration was happening between frontline and backroom staff—and that we were really missing some great opportunities. As I was developing my interest in readers services my thoughts focused on the idea that library catalogs can provide users with an interactive, social environment based on trust, familiarity, and a sense of belonging, just like the physical library. What we need to do is focus on what we offer-that special reason patrons visit our branches-and bring that into the catalog so that our remote and homebound patrons can take advantage of the same services that we offer within our physical walls. RA services seemed to be a natural fit and way to bring frontline and backroom staff together.

It was while shaping these thoughts and ideas about readers' services and exploring the idea of remote readers' advisory service that I met Barry Trott and Duncan Smith. Both Barry and Duncan allowed me further opportunities to shape my interest in readers' services, expanding it beyond my initial focus on the library catalog, into something larger, something that can happen anywhere at any time. This means that not only should the catalog become a readers' services platform, but so should our newsletters, websites, mobile devices and, of course, our in-house staff. But more than that, it's not about one small group or team within the library "owning" readers' services, but about all staff being encouraged to talk openly about books and to foster a collaborative space where patrons and staff are equals.

With that in mind, one of strengths of this column has been the ongoing contributions from many of you. This column isn't about my own specific ideas on readers' services because, like many of you, I am still learning about this unique and exciting service.

I welcome thoughts and ideas from other professionals who have implemented successful programs within their library, introduced innovative ideas, and have even failed miserably at an idea that they believed would be a hit. It is the collective ideas and the sharing of experiences that will continue Barry's legacy and continue the success of this column. This is a practice that I'd like to continue as editor. In fact, one of the most exciting aspects of this new position, to me, is the opportunity to meet many of you, to share ideas, and to develop not only working relationships, but friendships. I can think of no greater success than to know that all of you feel that this column is yours, not mine. And I want to emphasize that I welcome your thoughts and ideas, as well as contributions. And so, it is at this moment that I am putting in a shameless plug that if you are interested in writing as a guest columnist, or know of someone who should be invited to write an article, please contact me.

As some of you may know, although I'm American, I currently reside in Canada and have done so for over 10 years. Having had the opportunity to experience life in two countries has, I hope, made me aware of unique problems and library practices that are not a "one size fits all" application—from town to town and country to country. Because of this, I hope to welcome new, international voices as authors into this column. Perhaps we may be able to hear about readers' services from a small public library in Newfoundland or a success story out of Australia. I will do my best to seek out new professionals, as well as hard-working, dedicated, and experienced professionals who want to share their ideas and thoughts on existing readers' services practices as well as their vision for the future of readers' services. At times, the column may take a closer look at mobile devices or a certain aspect of social technology that may be useful in offering readers' services remotely and at other times, a traditional approach will be taken, such as sharing thoughts on training new readers' advisors.

I don't view this column as "mine" but rather "ours." As a result, the articles that are chosen and the authors that are invited to contribute will be shaped on the feedback I receive from you, the practicing readers' advisors. I hope that, as editor, many of you will contact me with thoughts, ideas, and constructive feedback. It is also important to me to make connections with many of you so that this column remains relevant and important, one that each of you eagerly awaits with the arrival of each issue.

We're in the midst of an exciting time in the library world. Some of our traditional core services are being questioned, while others, like readers' services, are growing in popularity and appear to be filling a need in our community that extends beyond physical boundaries and fits naturally into this fast-paced, digitally focused, on-demand world. I think all of us look forward to hearing about the ways many of you, our colleagues, are addressing these needs and changes in a variety of creative and innovative ways.

With great fondness we bid Barry goodbye as column editor and eagerly look forward to his guidance and mentorship as the new editor of RUSQ. And so, for now, as I take a deep breath and remind myself that I can do this, I hope that all of you are also looking forward to this journey that we will be taking together. And, to quote Barry earlier in this article, "that really is the goal, I believe, for any column, that it serve not as an ending point but as a beginning for reflection, discussion, and then application of the ideas it promotes." 